American J. of Engineering and Applied Sciences 3 (2): 333-341, 2010

ISSN 1941-7020

(C) 2010 Science Publications

\title{
Integrating Renewable and Nonrenewable Energies in Power Plant Planning
}

\author{
${ }^{1}$ Habib H. Al-Ali, ${ }^{2}$ Yousef Saif, ${ }^{2}$ Ali Elkamel and ${ }^{3}$ Ali Lohi \\ ${ }^{1}$ Department of Chemical Engineering, \\ King Fahd University of Petroleum and Minerals, Saudi Arabia \\ ${ }^{2}$ Department of Chemical Engineering, University of Waterloo, \\ ${ }^{3}$ Department of Chemical Engineering, Ryerson University, \\ Toronto ON M5B2K3, Canada
}

\begin{abstract}
Problem statement: Electricity can be generated from different type of technologies such as fossil and non-fossil power plants. Among these technologies, coal-fired power plants have been a major route for electricity generation. Recently, environmental constraints were imposed over the coal power plant operations in order to reduce their emissions. Besides, renewable energy power plants such as hydroelectric, wind, solar and geothermal have emerged with a potential of low impact on the environment. Approach: In this study, coal-fired power plants with a mix of low emission power plants were analyzed from the viewpoint of coal power plant emission reductions while supplying electricity demand. Electricity capacity expansion was also included within the problem to insure sufficient electricity supply in circumstances of emission reduction constraints. Results: Pollutants such as Nitrogen Oxides $\left(\mathrm{NO}_{\mathrm{x}}\right)$, Sulfur Oxides $\left(\mathrm{SO}_{\mathrm{x}}\right)$ and mercury $(\mathrm{Hg})$ were assumed to be the target compounds. A discrete mathematical programming model was formulated to give an assessment about the coal-fired power plant operations in an electricity generation network. Different scenarios of increased electricity demand and emission reduction targets were applied on Ontario Power Generation (OPG) network to give an illustration of the proposed model. Conclusion: The case study results show the significant impact of combining renewable energy or zero emission technologies on the optimal operation of a network that combines coal-fired power plants.
\end{abstract}

Key words: Coal power plants, renewable energy power plants, multi-pollutant emissions, optimal electricity production planning

\section{INTRODUCTION}

The increased demand of electricity is driven mainly by the expansion of residential, commercial and industrial sectors in every country all over the world. Traditionally, electricity have been generated from fossil fuels power plants (e.g., coal) due to the large amount of coal reservoir and the relatively coal cheap prices, precisely in North America. In addition, coal combustion processes produce large amount of emissions that have drastic effects on the environment and public health. These effects have raised several constraints on coal power plant operations to reduce the airborne emissions. On the other hand, there many technologies that relay on natural resources, such as hydroelectric, wind, geothermal and wind power plants. Current estimate of energy production from renewable energy sources is $14 \%$ of the total world energy demand. The future of electricity generation will be controlled by different factors, such as the economy of power production technologies and more importantly their environmental impacts.

Gaseous $\mathrm{SO}_{\mathrm{x}}$ (e.g., $\mathrm{SO}_{2}$ ) and $\mathrm{NO}_{\mathrm{x}}$ emissions have direct threat on human health due to their role as precursor which lead to the formation of a secondary particulates, a constituent of particulate matter. Fine particle can reach very sensitive parts of the lung which may cause serious health problems. Besides, reaction of $\mathrm{SO}_{\mathrm{x}}$ and $\mathrm{NO}_{\mathrm{x}}$ emissions with water, oxygen and oxidants in air leads to the formation of various acidic compounds. These compounds normally deposit in wet forms (e.g., acidic rain, fog) and in dry conditions (e.g., acidic gases, particulate). Acid deposition leads to negative changes in the environment such as altering water $\mathrm{pH}$, releasing Aluminum from soil and damaging plant tissues. Mercury can be in the form of element, ion, or particulate as a result of coal combustion. Exposure to $\mathrm{Hg}$ compounds lead to impaired growth

Corresponding Author: Habib H. Al-Ali, Department of Chemical Engineering, KFUPM, P.O. Box 1535, Dhahran 31261, Saudi Arabia 
Am. J. Engg. \& Applied Sci., 3 (2): 333-341, 2010

and development, behavioral abnormality and death. The aforementioned risks have led the Environmental Protection Agency (EPA) to set up strict regulations on coal-fired power plant emissions (Energy Information Administration, 2000).

In response to the Clean Air Act Amendment 1990, several mitigation policies were proposed to cope with the coal-fired power plant emissions. These may include power plant efficiency enhancement, fuel balancing, shifting toward other type of fuels (e.g., natural gas), installation of capture processes for the target pollutants and increasing the electricity production from renewable energy technologies and nuclear plants. These strategies require intensive evaluations within the scope of a single power plant and a fleet wide power generation system (Energy Information Administration, 2000; Rubin et al., 2004).

Coal power plants essentially burn coal in a boiler to generate steam. Afterwards, the steam under high pressure and temperature drives gas turbines with electrical generators to produce electricity. The thermal efficiency of these plants ranges between 35-47\% for subcritical plants and supercritical plants, respectively. Integrated Gasification Combined Cycle (IGCC) plants represent the state of the art in electricity generation with coal fuel. These plants require the production of syngas in a gasification unit. Several clean up processes can be integrated to clean $\mathrm{CO}_{2}$ and sulfur compounds prior to the combustion process. After the combustion of syngas, the superheated gas runs gas turbine units. The exhaust from these units can generate steam that further runs steam turbine units to produce more electricity. In general, the IGCC plants are more efficient than PC plants and have lower emissions, however, the IGCC plants are still more expensive (Rubin et al., 2001; 2004).

Flue gas treatment equipments normally exist in the chemical and petrochemical industries. These equipments can also be applied for the treatment of the flue gas in power plants. Due to the differences in the production scale, flue gas characteristics and the required treatment in power plants, several technologies were developed to achieve the emission reduction in power plants. These technologies were either developed to capture a single pollutant or multi-pollutant present in the flue gas streams. A comprehensive review of these technologies was reported in a thorough study prepared by (EPA) (Tavoulareas and Jozewicz, 2005).

The current research presents a discrete optimal production planning and expansion model for electricity generation from power generation network. The optimization model is formulated as an MINLP which decides upon the optimal operation of a power generation network, the selection of capture processes of multi-pollutant present in the flue gas streams, operation of renewable energy power plants. Different scenarios are covered to study the effects of increasing electricity demand and emission reduction on the optimal operation of the network. The literature review gives the different models related to the power generation. This is followed by the problem statement and a description of the power generation network superstructure. Next, the MINLP model is given to describe the mathematical programming formulation. Afterwards, different scenarios are presented to analyze the results of the model. A discussion of the current research will be given in the conclusion.

Literature review: The environmental impact of power generation with coal-based fuels has driven extensive research to retrofit and build new plants with minimum airborne gas emissions. The trend of the studies shows improvement of single plants and network of power plants. A systematic modeling framework that provides preliminary cost and performance assessments of coalfired power plants was developed under the name of Integrated Environmental Control Model (IECM) at the center for energy and environmental studies, Carnegie Mellon University. The software simulates the performance of coal-fired power plants with the consideration of multi-pollutant emission control technologies (Rubin et al., 2001).

Optimal utilization of coal fuel with a fleet of coalfired power plant was presented as a Linear Programming (LP) model. The coal supply points were linked to washing/cleaning plants, power plants and finally the demand market. This formulation of the network gives assessment of the viability of coal as a fuel taking into consideration $\mathrm{CO}_{2}$ emission constraints. The formulation of the mathematical program presents an example of the transportation problem and the applicability of the LP model was demonstrated on India (Mathur et al., 2003).

A linear programming model is formulated to assist the effects of natural gas fuel, different power generation technologies and capacity and the cost of $\mathrm{CO}_{2}$ sequestration on the carbon capture and storage mitigation viability for a network of coal-fired power plants. The sensitivity analysis shows that the natural gas being at a lower price eliminates the CCS mitigation. It also shows that when $\mathrm{CO}_{2}$ has an economical value (e.g., enhanced oil recovery applications) and very low coal prices, CCS becomes an attractive to maintain constrained emission limitations. However, the assessment does not provide solid judgment about the effects of other technologies 
Am. J. Engg. \& Applied Sci., 3 (2): 333-341, 2010

on CCS (Johnson and Keith, 2004). It also suggests that other pollutants such as $\mathrm{NO}_{\mathrm{x}}, \mathrm{SO}_{\mathrm{x}}$ and $\mathrm{Hg}$ will have influence on the CCS mitigation. Fluctuation of electricity demand from a base-load demand, operation of existing plants, investment and operation of new technologies was studied to perform evaluation of CCS mitigation under different $\mathrm{CO}_{2}$ emission constraints. Also, the investment of new technologies such as IGCC was considered in the model. The results show pronounced effect of electricity variations on the optimal mitigation of $\mathrm{CO}_{2}$ emission (Wise and Dooley, 2004).

Carbon capture processes consume significant amount of energy that should be supplied from the plant itself or from an external source. This energy penalty will in general affect the plant output and the electricity cost. To compromise with the electricity consumption through capture processes, several technologies such as IGCC, NGCC and renewable sources as well as PC were integrated with coal-fired plants to supply the electricity demand. Therefore, the total power production from a mix of technologies was studied to analyze the effect of capture processes on the Cost Of Electricity (COE) (Narula et al., 2002). A study considered the previous issues shows that the power generation mix and fuel prices have strong impact on the COE. In general, with lower cost of coal compared with natural gas and improving the carbon capture processes, PC plants will be competitive. With an increase of $\mathrm{CO}_{2}$ emission restrictions, the $\mathrm{COE}$ will likely to increase over time (Rubin et al., 2007).

Optimization of a network with discrete decisions helps to compare different alternatives of electricity generation design with respect to a given criterion (e.g., economical objective, emission reductions). This modeling approach has be been adopted to optimize the supply chain problem of a fleet wide generation of power plants with environmental consideration. The coal-fired plants, natural gas plants and renewable energy plants were optimized to supply a fixed demand while minimizing $\mathrm{CO}_{2}$ emissions. The model takes into consideration electricity capacity expansion and $\mathrm{CO}_{2}$ capture and sequestration. A case study of Ontario Power Generation (OPG) is considered as an application of the mathematical programming model (Mirzaesmaeeli, 2007).

Production planning encompasses prediction of future events which are associated with uncertainty. Optimal electricity production planning resembles conditions of uncertain product demand and facility production throughput. Forecasting of peak and base load electricity demands was modeled based on linear/multiple regression techniques to predict long term electricity needs (Chui, 2007). Uncertainty of fuel prices (e.g., coal, natural gas) and electricity demand were considered as random variables in a robust mathematical program to analyze optimal electricity from a power generation fleet that rely on fossil fuel power plant (e.g., coal, natural gas) and nuclear power plants. The robust formulation takes into consideration $\mathrm{CO}_{2}$ reduction target. Another stochastic MILP formulation considered power planning expansion formulation from fossil fuel and hydroelectric power generation network (Liu et al., 2008). A different modeling approach of power production planning and facility expansion of mixed power plants is formulated as a multi-period mathematical programming formulation. The model considered different mix of fossil fuel power plants with $\mathrm{CO}_{2}$ capture processes, renewable energy plants and nuclear plants. In addition, several $\mathrm{CO}_{2}$ reduction target and increased electricity demand is embedded in the formulation (Mirzaesmaeeli, 2007). A decomposition algorithm for the multi-period energy supply system was presented to reduce the computational time (Yokoyama et al., 2002). In general, the stochastic and multi-period models provide more flexibility in presenting the electricity production planning and facility expansion problem compared with the deterministic static models.

Electricity production planning from existing power plants, emissions capture and minimization and optimal electricity generation expansion normally poses multiple conflicts of objectives. Multiple objectivebased mathematical programming models give tools to describe these conditions (Antunes et al., 2004; Linares and Romero, 2002). This approach allows evaluation of incompatible measures (e.g., economical, environmental, social) which in turn provides a compromise solution. Another advantage with the approach is the minimization of the environmental impact of emissions rather than giving upper bounds on their limitations. The framework of multiple objective optimization has been applied to model the optimal electricity production planning, capacity expansion and emission reductions in power plants.

Problem statement: It is assumed that the power generation network is composed of coal-fired power plants, existing renewable energy power plants and possibly new renewable energy power plants. This network supplies a predetermined electricity demand. Further, it is assumed that coal is the fuel consumed to run the coal-fired power plants. During the combustion process, the hot gas which runs the gas turbines contains $\mathrm{SO}_{\mathrm{x}}, \mathrm{NO}_{\mathrm{x}}$ and $\mathrm{Hg}$. The exhaust gases can be captured or emitted to the atmosphere based on the 
Am. J. Engg. \& Applied Sci., 3 (2): 333-341, 2010

emission constraints. The main goal of this study is to determine the optimal operation of power plant network to satisfy the electricity demand while maintaining acceptable emission levels to comply with environmental constraints. In addition, it is important to decide on the selection of new power plants that will satisfy an increased demand of electricity as well as capture processes on coal-fired power plants.

\section{MATERIALS AND METHODS}

Problem representation: The problem can be viewed as a network of different power plants that adopt different technologies to produce electricity. These technologies are represented in a graphical form in order to derive the mathematical programming model, Fig. 1. Coal-fired power stations, cs, is assumed to have several coal-fired power plants, i. Over every boiler at a given power plant, i, it is assumed that several capture processes, $\mathrm{j}$, that may exist to reduce the emissions of pollutants, $\mathrm{k}$. In addition, there is another set of existing renewable energy power plants, er. This set is composed of several types of renewable energy power plants. For example, hydroelectric, wind and geothermal are possible cases within the set. Further, every element e (e.g., technology type) has several number of power plants from a single type, $\mathrm{e}_{\mathrm{m}}$. The set nr represents hypothetical new renewable energy power plants. Different type of renewable energy power plants, $\mathrm{n}$, is assumed to have several power plants of the same type, $\mathrm{n}_{\mathrm{z}}$. This representation will provide view of the power plant network and will help to formulate the mathematical programming model.

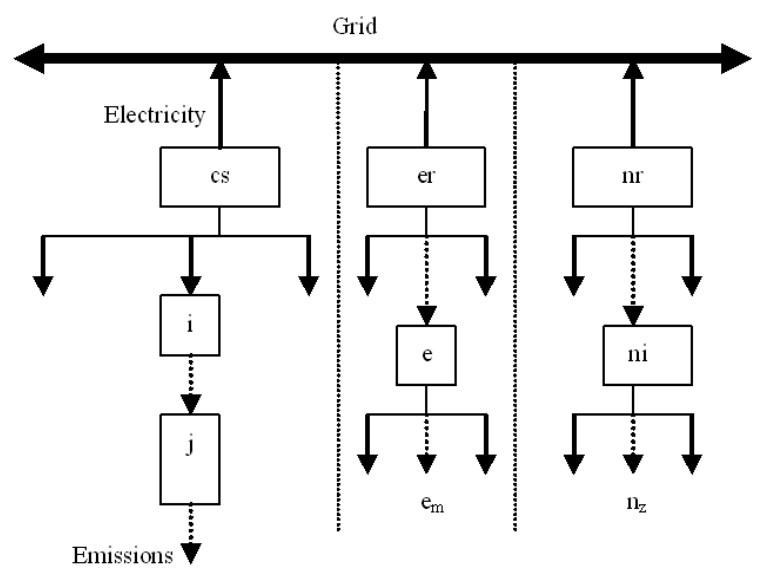

Fig. 1: Superstructure representation of coal-fired power plants
Approach: Discrete variables help to model the existence of unit operations in process synthesis problems. These binary variables will provide decisions about the selection of capture processes, as well as installation of new power plants. 0/1 binary variables, $\mathrm{y}_{\mathrm{cs}, \mathrm{i}, \mathrm{j}, \mathrm{are}}$ introduced in the model formulation to define the existence of capture process $j$ on a boiler $i$ at a coal power station cs. Every boiler i at a coal station cs produces electricity, $\mathrm{E}_{\mathrm{cs}, \mathrm{i}}$, as a result of coal combustion in the plant. The existing renewable energy power plant may produce electricity, $\mathrm{E}_{\mathrm{er}, \mathrm{e}, \mathrm{em}}$, if their operation will be optimum to supply portion of the overall electricity demand and help to reduce the emission flow. $\mathrm{Y}_{\mathrm{nr}, \mathrm{n}, \mathrm{nz}}$ is a binary variable which defines the existence of a power plant $n_{z}$, whereas $Y_{n r, n, n z}$ defines the electricity production from plant $n_{z}$. The objective function is defined as to minimize the total annualized cost TACas follows:

$$
\begin{aligned}
\mathrm{TAC}= & \sum_{\mathrm{cs}} \sum_{\mathrm{i}} \mathrm{C}_{\mathrm{cs}, \mathrm{i}}^{\mathrm{Eop}} \mathrm{E}_{\mathrm{cs}, \mathrm{i}} \\
& +\sum_{\mathrm{cs}} \sum_{\mathrm{i}} \sum_{\mathrm{j}}\left(\mathrm{C}_{\mathrm{cs}, \mathrm{i}, \mathrm{j}}^{\mathrm{Capf}}+\mathrm{C}_{\mathrm{cs}, \mathrm{i}, \mathrm{j}}^{\mathrm{Capo}}\right) \mathrm{E}_{\mathrm{cs}, \mathrm{i}} \mathrm{y}_{\mathrm{cs}, \mathrm{i}, \mathrm{j}} \\
& +\sum_{\mathrm{er}} \sum_{\mathrm{e}} \sum_{\mathrm{e}_{\mathrm{m}}} \mathrm{C}_{\mathrm{er}, \mathrm{e}, \mathrm{e}_{\mathrm{m}}}^{\mathrm{ero}} \mathrm{E}_{\mathrm{er}, \mathrm{e}, \mathrm{e}_{\mathrm{m}}} \\
& +\sum_{\mathrm{nr}} \sum_{\mathrm{n}} \sum_{\mathrm{n}_{\mathrm{z}}} \mathrm{C}_{\mathrm{nr}, \mathrm{n}, \mathrm{n}_{\mathrm{z}}}^{\mathrm{nrf}} \mathrm{y}_{\mathrm{nr}, \mathrm{n}, \mathrm{n}_{\mathrm{z}}} \\
& +\sum_{\mathrm{nr}} \sum_{\mathrm{n}} \sum_{\mathrm{n}_{\mathrm{z}}} \mathrm{C}_{\mathrm{nr}, \mathrm{n}, \mathrm{n}_{\mathrm{z}}}^{\mathrm{nro}} \mathrm{E}_{\mathrm{nr}, \mathrm{n}, \mathrm{n}_{\mathrm{z}}}
\end{aligned}
$$

Where:

$\mathrm{C}_{\mathrm{cs}, \mathrm{i}}^{\mathrm{Eop}}=$ The operating cost coefficient of a boiler $\mathrm{i}$ at $\mathrm{a}$ coal power station cs

$\mathrm{C}_{\mathrm{cs}, \mathrm{i}, \mathrm{j}}^{\mathrm{Capf}}=$ Gives the fixed cost coefficient of a capture process $\mathrm{j}$ on a boiler $\mathrm{i}$ at a coal power station cs

$\mathrm{C}_{\mathrm{cs}, \mathrm{i}, \mathrm{j}}^{\mathrm{Capo}}=$ Stands for the operating cost of a capture process $\mathrm{j}$ on a boiler $\mathrm{i}$ at a coal power station cs $\mathrm{C}_{\mathrm{er}, \mathrm{e}, \mathrm{e}_{\mathrm{m}}}^{\mathrm{ero}}=$ Gives the operating cost coefficient for operating existing renewable power plant

$\mathrm{C}_{\mathrm{nr}, \mathrm{n}, \mathrm{n}_{\mathrm{z}}}^{\mathrm{nr}}=$ Represents the fixed cost coefficient for the new renewable energy power plant

$\mathrm{C}_{\mathrm{nr}, \mathrm{n}, \mathrm{n}_{\mathrm{z}}}^{\mathrm{nro}}=$ Gives the operating cost coefficient for a new renewable power plant

The first term in the objective function represents the operating cost of coal plants. The second and third terms give the fixed and operating costs of the capture processes, respectively. The fourth term gives the operating cost of existing renewable power plant. The 
last two terms in the objective function represents the fixed and operating cost of new renewable energy power plants.

There are several constraints that limit the feasibility of the power generation network. For example a boiler $\mathrm{i}$ has a maximum production design capacity $E_{\mathrm{cs}, \mathrm{i}}^{\max }$ that should not be exceeded during operation. Also, the existing and renewable energy power plants have similar constraints, Eq. 2-4:

$$
\mathrm{E}_{\mathrm{cs}, \mathrm{i}} \leq \mathrm{E}_{\mathrm{cs}, \mathrm{i}}^{\max }
$$

$$
\mathrm{E}_{\mathrm{er}, \mathrm{e}, \mathrm{e}_{\mathrm{m}}} \leq \mathrm{E}_{\mathrm{er}, \mathrm{e}, \mathrm{e}_{\mathrm{m}}}^{\mathrm{max}}
$$

$$
\mathrm{E}_{\mathrm{nr}, \mathrm{n}, \mathrm{n}_{\mathrm{z}}} \leq \mathrm{E}_{\mathrm{nr}, \mathrm{n}, \mathrm{n}_{\mathrm{z}}}^{\max }
$$

It can also be stated that the maximum feasible electricity production from all power plants in the network as:

$$
\begin{aligned}
& \sum_{\mathrm{cs}} \sum_{\mathrm{i}} \mathrm{E}_{\mathrm{cs}, \mathrm{i}}+\sum_{\mathrm{er}} \sum_{\mathrm{e}} \sum_{\mathrm{e}_{\mathrm{m}}} \mathrm{E}_{\mathrm{er}, \mathrm{e}, \mathrm{e}_{\mathrm{m}}}+\sum_{\mathrm{nr}} \sum_{\mathrm{n}} \sum_{\mathrm{n}_{\mathrm{z}}} \mathrm{E}_{\mathrm{nr}, \mathrm{n}, \mathrm{n}_{\mathrm{z}}} \\
& \leq \text { SEPMAX }
\end{aligned}
$$

Constraint 5 defines the maximum throughput of the all power plants in the network. In another word, the model will declare infeasibility if the electricity demand is higher than the sum of the maximum electricity production capacity of the network (SEPMAX).

There may be operational constraints that are compulsory on the existing power plants. These constraints may require a threshold on increasing electricity production from a base operation due to limitations of the power plant design. Mathematically, this condition is described as:

$$
\begin{aligned}
& \mathrm{E}_{\mathrm{cs}, \mathrm{i}} \leq(1+\mathrm{R}) \mathrm{E}_{\mathrm{cs}, \mathrm{i}}^{\text {current }} \\
& \mathrm{E}_{\mathrm{er}, \mathrm{e}, \mathrm{e}_{\mathrm{m}}} \leq(1+\mathrm{R}) \mathrm{E}_{\mathrm{er}, \mathrm{e}, \mathrm{e}_{\mathrm{m}}}^{\text {curent }} \\
& \mathrm{E}_{\mathrm{nr}, \mathrm{n}, \mathrm{n}_{\mathrm{z}}} \leq(1+\mathrm{R}) \mathrm{E}_{\mathrm{nr}, \mathrm{n}, \mathrm{n}_{\mathrm{z}}}^{\text {current }}
\end{aligned}
$$

Since the electricity demand, D, is a fixed value that should be satisfied, the model will optimize the electricity generation from all power plants. This will result of fuel balancing from coal power plants, operation of existing renewable energy power plants and decision of installation new renewable energy power plants in order to satisfy the electricity needs: $\sum_{\mathrm{cs}} \sum_{\mathrm{i}} \mathrm{E}_{\mathrm{cs}, \mathrm{i}}+\sum_{\mathrm{er}} \sum_{\mathrm{e}} \sum_{\mathrm{e}_{\mathrm{m}}} \mathrm{E}_{\mathrm{er}, \mathrm{e}, \mathrm{e}_{\mathrm{m}}}+\sum_{\mathrm{nr}} \sum_{\mathrm{n}} \sum_{\mathrm{n}_{\mathrm{z}}} \mathrm{E}_{\mathrm{nr}, \mathrm{n}, \mathrm{n}_{\mathrm{z}}} \geq \mathrm{D}$

Environmental constraints on every pollutant, k, should comply with the maximum allowable limits that are set up by the environmental regulations for every boiler under operation as follows:

$\sum_{\mathrm{cs}} \sum_{\mathrm{i}} \mathrm{F}_{\mathrm{cs}, \mathrm{i}, \mathrm{k}}^{\mathrm{R}} \leq \mathrm{F}_{\mathrm{k}}^{\max } \quad \forall \mathrm{k}$

Where:

$\mathrm{F}_{\mathrm{cs}, \mathrm{i}, \mathrm{k}}^{\mathrm{R}}=$ Stands for the flow of pollutant $\mathrm{k}$ that is released from boiler $i$ at power station cs

$\mathrm{F}_{\mathrm{k}}^{\max }=\mathrm{A}$ threshold limit of a pollutant $\mathrm{k}$ release to the atmosphere

The role of capture processes is to reduce the total emissions release to the atmosphere. In the mathematical formulation, the binary variables $\mathrm{y}_{\mathrm{cs}, \mathrm{i}, \mathrm{j}}$ are related to the amount of pollutants $\mathrm{F}_{\mathrm{cs}, \mathrm{i}, \mathrm{j}, \mathrm{k}}^{\mathrm{CAP}}$ that are captured in the process as follows:

$\mathrm{F}_{\mathrm{cs}, \mathrm{i}, \mathrm{j}, \mathrm{k}}^{\mathrm{CAP}} \leq \mathrm{F}_{\mathrm{k}, \mathrm{j}}^{\mathrm{CAP}-\mathrm{max}} \mathrm{y}_{\mathrm{cs}, \mathrm{i}, \mathrm{j}} \quad \forall \mathrm{cs}, \mathrm{i}, \mathrm{j}, \mathrm{k}$

$\mathrm{F}_{\mathrm{k}, \mathrm{j}}^{\mathrm{CAP}-\mathrm{max}}$ gives an upper bound on the amount of pollutant $\mathrm{k}$ that can be captured with the capture process j. Equation 6 defines the existence of a capture process $\mathrm{j}$. Mass balance for every pollutant $\mathrm{k}$ at every boiler $\mathrm{i}$ in a station cs can be described as;

$\mathrm{F}_{\mathrm{cs}, \mathrm{i}, \mathrm{k}}=\mathrm{F}_{\mathrm{cs}, \mathrm{i}, \mathrm{k}}^{\mathrm{R}}+\sum_{\mathrm{j}} \mathrm{F}_{\mathrm{cs}, \mathrm{i}, \mathrm{j}, \mathrm{k}}^{\mathrm{CAP}} \quad \forall \mathrm{cs}, \mathrm{i}, \mathrm{k}$

In this study, the emission of every pollutant $\mathrm{k}$ is related to the electricity produced at every boiler $E_{c s, j}$ as:

$\mathrm{F}_{\mathrm{cs}, \mathrm{i}, \mathrm{k}}=\alpha_{\mathrm{k}} \mathrm{E}_{\mathrm{cs}, \mathrm{i}} \quad \forall \mathrm{cs}, \mathrm{i}, \mathrm{k}$

where, $a_{k}$ represents proportional constant between the electricity produced and the emission of pollutant $\mathrm{k}$ at a boiler i.

The existing of new renewable energy plants are relation between the electricity production and their binary variables. These plants will not produce electricity if the evaluation of the binary variables is zero. Equation 14 represents the relation as: 
Am. J. Engg. \& Applied Sci., 3 (2): 333-341, 2010

$\mathrm{E}_{\mathrm{nr}, \mathrm{n}, \mathrm{n}_{\mathrm{z}}} \leq \mathrm{E}_{\mathrm{nr}, \mathrm{n}, \mathrm{n}_{\mathrm{z}}}^{\max } \mathrm{y}_{\mathrm{nr}, \mathrm{n}, \mathrm{n}_{\mathrm{z}}}$

Equation 1-4 and 6-14 give a nonconvex MINLP model of the power plant network. The nonconvex terms in the objective function produce bilinear functions as a result of a multiplication of a binary variable, $\mathrm{y}_{\mathrm{css}, \mathrm{i}, \mathrm{j}}$, with a continuous variable $\mathrm{E}_{\mathrm{cs}, \mathrm{i}}$. The problem can be reformulated to give convex mathematical program through the introduction of additional variables and constraints as follows:

$\eta_{\mathrm{cs}, \mathrm{i}, \mathrm{j}}=\mathrm{E}_{\mathrm{cs}, \mathrm{i}} \mathrm{y}_{\mathrm{cs}, \mathrm{i}, \mathrm{j}}$

$0 \leq \eta_{\mathrm{cs}, \mathrm{i}, \mathrm{j}} \leq \mathrm{E}_{\mathrm{cs}, \mathrm{i}}$

$\mathrm{E}_{\mathrm{cs}, \mathrm{i}}-\mathrm{M}\left(1-\mathrm{y}_{\mathrm{cs}, \mathrm{i}, \mathrm{j}}\right) \leq \eta_{\mathrm{cs}, \mathrm{i}, \mathrm{j}} \leq \mathrm{My_{ \textrm {cs } , \mathrm { i } , \mathrm { j } }}$

Equation 15 replaces the nonconvex term in the objective function by a continuous variable, $\eta_{\mathrm{cs}, \mathrm{i}, \mathrm{j}}$. If the binary variable, $\mathrm{y}_{\mathrm{cs}, \mathrm{i}, \mathrm{j}}$ has a value of one, then Eq. 15-17 insures that the value of the continuous variable $\eta_{\mathrm{cs}, \mathrm{i}, \mathrm{j}}$ matches the electricity produced $\mathrm{E}_{\mathrm{cs}, \mathrm{i}}$. On the other hand, if the binary variable, $\mathrm{y}_{\mathrm{cs}, \mathrm{i}, \mathrm{j}}$, has zero value, then Eq. 16-17 forces the continuous variable $\eta_{\mathrm{cs}, \mathrm{i}, \mathrm{j}}$ value to have zero. $\mathrm{M}$ represents a big number value. Therefore, the set of Eq. 15-17 reformulates the nonconvex program into mixed integer linear program.

\section{RESULTS AND DISCUSSION}

Ontario Power Generation (OPG) operates several coal and renewable energy power plants. There are five coal-fired power stations in Lambton (L), Nanticoke (N), Lakeview (LV), Atikokan (A) and Thunder Bay (TB). Lambton has 4 boilers, Nanticoke has 8 boilers, Lakeview has eight boilers, Atikokan has one and Thunder Bay has 2 boilers. Therefore, twenty three coal-fired boilers correspond to sources of $\mathrm{SO}_{\mathrm{x}}, \mathrm{NO}_{\mathrm{x}}$ and $\mathrm{Hg}$ emissions. In addition, there are 69 hydroelectric power plants and a small wind power plant. In this study, nuclear plants are added to the case study since their electricity generation produces almost zero emission. In Ontario, there are 3 nuclear power plants. Also, it is assumed that the capacity expansion in this case study was considered as a decision to build new nuclear power plants.
There are several pollution abatement technologies that can be used to control the $\mathrm{NO}_{\mathrm{x}}$ emissions. Selective Catalytic Reduction (SCR) process involves converting $\mathrm{NO}_{\mathrm{x}}$ with the aid of a catalyst into nitrogen and water in the presence of oxygen. Selective Non-Catalytic Reduction (SNCR) process involves injecting either ammonia or urea into the firebox of the boiler at high temperature locations (e.g., $1600-2100^{\circ} \mathrm{F}$ ). It then reacts with the nitrogen oxides formed in the combustion process to produce nitrogen, carbon dioxide and water. Coal Re-burning (CR) technology is a process to condition the coal (pulverized coal) before the combustion process.

Wet Flue Gas Desulfurization (WFGD) process involves scrubbing $\mathrm{SO}_{2}$ by using alkaline slurry made by adding lime $(\mathrm{CaO})$ to water. The alkaline slurry is sprayed into the exhaust stream and reacts with $\mathrm{SO}_{2}$. Insoluble sulfur salts form as a solid by-product. Dry Flue Gas Desulfurization (DFGD) process consists of the atomization of an alkaline reagent slurry via rotary atomizers or pneumatic nozzles. It is then injected into a vessel where it reacts with the $\mathrm{SO}_{2}$ in the flue gas to produce sulfate products. Flue gas exiting the spray dryer is directed into Electro Static Precipitator (ESP) to collect the dry material or partially introduced to an absorber with a slurry mixture to enhance the overall efficiency of the process.

Activated Carbon Injection (ACI) with particulate control (e.g., ESP) involves the injection of activated carbon powder into the flue gas stream. Vapor phase $\mathrm{Hg}$ is adsorbed onto the activated carbon which is then collected in the ESP.WFGD with mercury oxidation controls the emission of two pollutants, $\mathrm{SO}_{2}$ and $\mathrm{Hg}$. Reagent-based oxidants can be injected in the flue gas or in the WFGD scrubber to promote $\mathrm{Hg}$ oxidation. These technologies of $\mathrm{NO}_{\mathrm{x}}, \mathrm{SO}_{\mathrm{x}}$ and $\mathrm{Hg}$ are adopted in the mathematical programming formulation by including several capture processes over every boiler in order to reduce the boiler emissions.

The analysis of the case study will focus first on the set of coal-fired power plants as an attempt to see the effect of other technologies. Afterwards, the renewable energy power plants (existing and new) will be included in different scenarios of increased electricity demand and emission reduction targets. This is a summary of the scenarios covered in this case study:

- Optimization a base case to find out the optimal generation from the existing power plants in order to satisfy the electricity demand and emission constraints. This is accomplished by fuel balancing, capture processes on coal-fired power plants and renewable energy power plants 
Am. J. Engg. \& Applied Sci., 3 (2): 333-341, 2010

- Optimization the power plant network to achieve increased electricity demand with reduction targets of 20,40 and $60 \%$ for every pollutant from the actual base case. In these scenarios expansion of the existing power plants network is included to supply the electricity shortage of the power plant network

The first point addresses the correction or adjustment of current production of electricity from the existing power plant network. The second scenario addresses reduction targets that can be implemented within the network to satisfy future electricity demand with emission restrictions and capacity expansion of the existing network.

It is assumed that the base case corresponds to an electricity demand of 58,907,495 MWh year ${ }^{-1}$. Also, the emission constraints over the pollutants should not exceed 3,593 ton year ${ }^{-11}$. for $\mathrm{NO}_{\mathrm{x}}, 23,833$ ton year ${ }^{-1}$. for $\mathrm{SO}_{\mathrm{x}}$ and 0.0561 ton year ${ }^{-1}$ for $\mathrm{Hg}$. The results of the optimization show that coal-fired power plants share the supply of electricity with the renewable energy plants. Besides, the electricity production from coalfired power plants does not require installation of capture processes for the target pollutants. The total electricity production is $5.890749 \mathrm{E}+7 \mathrm{MWh}_{\mathrm{year}}{ }^{-1}$. Figure 2 show the distribution of electricity production among the existing technologies. It can be seen that the major production of electricity is supplied through hydro and coal-fired power plants. The nuclear plants do not share any portion of the electricity production. The total cost of the electricity production is \$495.6E6 year $^{-1}$. In addition, the overall pollutant releases for $\mathrm{NO}_{\mathrm{x}}, \mathrm{SO}_{\mathrm{x}}$ and $\mathrm{Hg}$ are 2639.09, 14987.1, 0.020 , respectively which are below their limits.

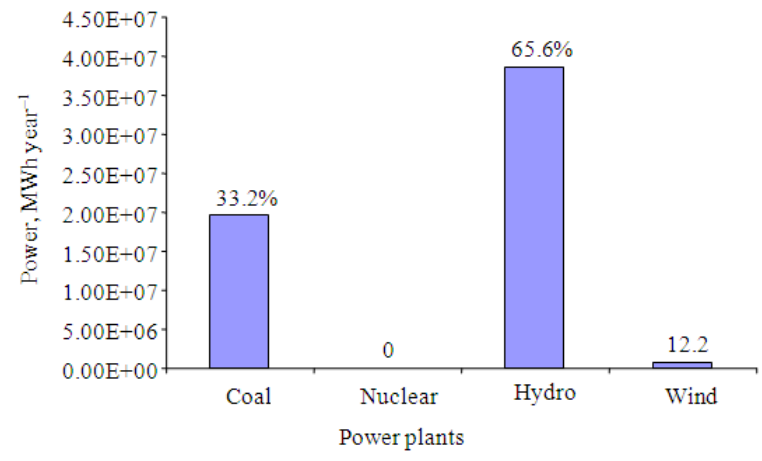

Fig. 2: Electricity production distribution for the base case
The increase of electricity demand may require adjustment of the electricity production planning from the mixed technologies within the network while satisfying the emission constraints. Figure 3 shows the trend of increasing the demand of electricity while maintaining the emission constraints at the base case limits. With increasing the demand, the coal -fired power plants supply the grid with higher production rate than the base case. Besides, the supply of electricity from coal-fired power plants is limited by the emission constraints. In fact, the electricity supply from coal-fired power plants remains at a level of 3.11E+07 MWh year ${ }^{-1}$. This is due to the trade off between the fixed and operating cost associated with installing capture processes with the operation of existing non-fossil power plants (e.g., nuclear plants). Within the range of the electricity production planning (i.e., increasing the electricity demand by $20,30,50 \%$ from the base case), the electricity production from the existing power plants are also limited by their operational limits constraints. As a result, the expansion of the existing power plant fleet will require installation of new power plants to satisfy the electricity demand and the emission constraints.

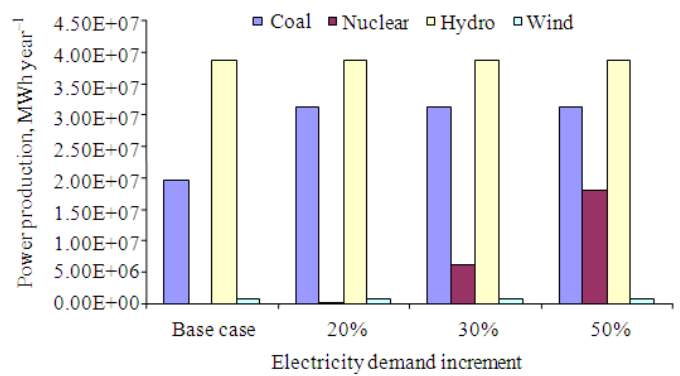

Fig. 3: Proportion of electricity generation from the different technologies with increased demand

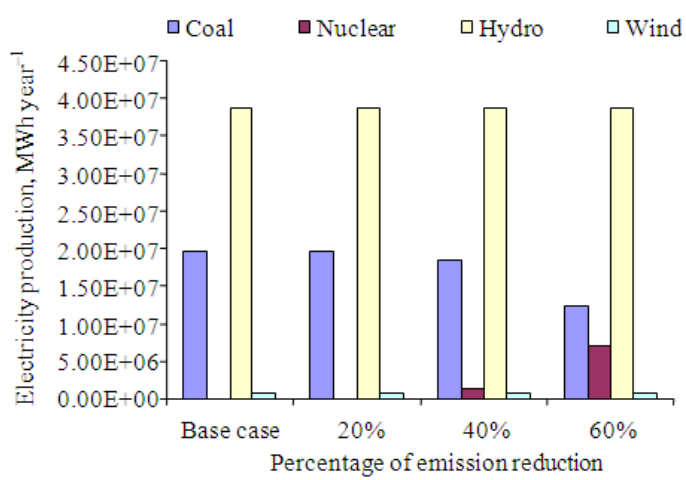

Fig. 4: Electricity production mixed from power plants under different emission reduction targets 
Am. J. Engg. \& Applied Sci., 3 (2): 333-341, 2010

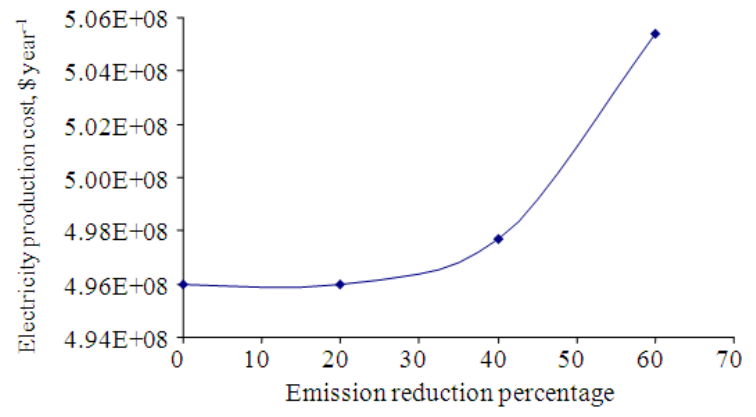

Fig. 5: Electricity production cost versus emission reduction targets

The effect of emission reduction targets on the electricity production shares between the power plants is given in Fig. 4. It can be seen that the electricity produced from coal-fired power plants are reduced at high reduction targets. Simultaneously, the production from other technologies are either increased or remained at the same level. Besides, the reduction of electricity generation from coal-fired power plants was combined with capture processes for the emissions. This situation represents trade-off between the cost of electricity production and the capture processes. Figure 5 shows the effect of emission reduction on the overall electricity production cost from the power generation network. Generally, the trend shows an increase of the electricity production cost with the emission reduction requirement.

\section{CONCLUSION}

In this study, optimal production planning of electricity from a mixed of power plants was analyzed with the view of emission capture and reduction while maintaining sufficient electricity demand. The optimization model took into consideration different types of power plants. Coal-fired power plants are combined with zero emission power plant technologies to assist the production from coal-fired power plants and the effect of capture processes on the overall optimal operation of the network. Different scenarios of increasing electricity production and reduction targets of $\mathrm{NO}_{\mathrm{x}}, \mathrm{SO}_{\mathrm{x}}$ and $\mathrm{Hg}$ were undertaken to study their effects on the optimal production from a network of coal-fired power plants. A case study of Ontario Power Generation, OPG, was given as illustration of the proposed methodology.

The case study results show the significant impact of combining renewable energy or zero emission technologies on the optimal operation of a network that combines coal-fired power plants. Capture processes for the pollutants resulting from combustion coal play a major role on the coal optimal operation. In general, there is a tradeoff between installation of capture processes on coal-fired power plants and the operation of zero emission power plants. Besides, fuel balancing and electricity production distribution from all power plants may eliminate the need to install capture processes on the coal-fired power plants. Strictly speaking, the amount of electricity that can be produced from coal-fired power plants and the decisions about the capture processes depend on the allowable emission limits.

\section{ACKNOWLEDGMENT}

The researchers wish to thank KFUPM Saudi Arabia, UW for their support.

\section{REFERENCES}

Antunes, C.H., A.G. Martins and I.S. Brito, 2004. A multiple objective mixed integer linear programming model for power generation expansion planning. Energy, 29: 613-627. http://cat.inist.fr/?aModele=afficheN\&cpsidt=1721 0061

Chui, F.W.Y., 2007. An environmentally conscious robust optimization approach for planning power generating systems. MSc Thesis, University of Waterloo, Waterloo, Canada. http://uwspace.uwaterloo.ca/handle/10012/3117

Energy Information Administration, 2000. Analysis of strategies of reducing multiple emissions from power plants: Sulfur dioxide, nitrogen dioxide and carbon dioxide. SR/OIAF/2000-05, Washington, DC., USA. http://www.eia.doe.gov/oiaf/servicerpt/powerplants/

Johnson, T. and D.W. Keith, 2004. Fossil electricity and $\mathrm{CO}_{2}$ sequestration: How natural gas prices, initial conditions and retrofits determine the cost of controlling $\mathrm{CO}_{2}$ emissions. Energy Policy, 32: 367-382. http://cat.inist.fr/?aModele=afficheN\&cpsidt $=1511$ 5849

Linares, P. and C. Romero, 2002. Aggregation of preferences in an environmental economics context: A goal programming approach. Omega, 30: 89-95. DOI: 10.1016/S0305-0483(01)00059-7

Liu, Z.F., G.H. Huang and N. Li, 2008. A dynamic optimization approach for power generation planning under uncertainity. Energy Sources, Part A: Recovery. Utiliz. Environ. Effect., 30: 1413-1431. http://www.informaworld.com/smpp/ftinterface?co ntent $=$ a794227744\&rt $=0 \&$ format $=$ pdf 
Mathur, R., S. Chand and T. Tezuka, 2003. Optimal use of coal power generation in India. Energy Policy, 31: 319-331.

http://cat.inist.fr/?aModele=afficheN\&cpsidt=1442 1245

Mirzaesmaeeli, H., 2007. A multi-period optimization model for energy planning with $\mathrm{CO}_{2}$ emission consideration. MSc Thesis, University of Waterloo, waterloo, Canada.

http://uwspace.uwaterloo.ca/handle/10012/3418

Narula, R.G., H. Wen, K. Himmes and B. Power, 2002. Incremental cost of $\mathrm{CO}_{2}$ reduction in power plants. Proceeding of IGTI ASME Turbo EXPO, June 3-3, Amsterdam, Netherlands, pp: 1-8. http://users.rowan.edu/ jansson/spring07/advpowe rsys/2002Bechtel.pdf

Rubin, E., A. Rao and M. Berkenpas, 2001. A multipollutant framework for evaluating $\mathrm{CO}_{2}$ control options for fossil fuel power plants. Proceeding of the 1st National Conference on Carbon Sequestration, (NCCS'01), Washington DC., USA., $\quad$ pp: 1-18. http://www.netl.doe.gov/publications/proceedings/ 01/carbon_seq/2c2.pdf

Rubin, E., A. Rao and C. Chen, 2004. Comparative assessments of fossil fuel power plants with $\mathrm{CO}_{2}$ capture and storage. Proceeding of the 7th International Conference on Greenhouse Gas Control Technologies, (ICGGCT’04), Vancouver, Canada, pp: $1-9$. http://uregina.ca/ghgt7/PDF/papers/peer/475.pdf
Rubin, E.S., C. Chen and A.B. Rao, 2007. Cost and performance of fossil fuel power plants with $\mathrm{CO}_{2}$ capture and storage. Energy Policy, 35: 4444-4454. http://ideas.repec.org/a/eee/enepol/v35y2007i9p44 44-4454.html

Tavoulareas, E.S. and W. Jozewicz, 2005. Multipollutant emission control technology options for coal-fired power plants. US, Environmental Protection Agency Report No. EPA-600/R-05/034. http://www.epa.gov/airmarkt/resource/docs/multipr eport2005.pdf

Wise, M. and J.J. Dooley, 2004. Baseload and peaking economics and the resulting adoption of a carbon dioxide capture and storage system for electric power plants. Proceeding of the 7th International Conference on Greenhouse Gas Emissions, (ICCGE’044), Vancouver, Canada, pp: 1-9. http://uregina.ca/ghgt7/PDF/papers/peer/280.pdf

Yokoyama, R., Y. Hasegawa and K. Ito, 2002. A MILP decomposition approach to large scale optimization in structural design of energy supply systems. Energy Conver. Manage., 43: 771-790. DOI: 10.1016/S0196-8904(01)00075-9 